\title{
Kaempferol induces autophagic cell death of hepatocellular carcinoma cells via activating AMPK signaling
}

\author{
Bing Han ${ }^{1, *}$, Yi-Qun Yu ${ }^{1, *}$, Qi-Lian Yang ${ }^{1}$, Chun-Ying Shen ${ }^{1}$ and Xiao-Juan Wang ${ }^{1}$ \\ ${ }^{1}$ Department of Pharmacy, Minhang Hospital, Fudan University, Shanghai, China \\ *Co-first authors \\ Correspondence to: Bing Han, email: hanbingzylw8@163.com, hbshcn@163.com \\ Keywords: kaempferol, hepatocellular carcinoma (HCC), AMPK, autophagy, MAGE6 \\ Received: July 27, $2017 \quad$ Accepted: August 09, $2017 \quad$ Published: September 16, 2017 \\ Copyright: Han et al. This is an open-access article distributed under the terms of the Creative Commons Attribution License 3.0 \\ (CC BY 3.0), which permits unrestricted use, distribution, and reproduction in any medium, provided the original author and source \\ are credited.
}

\section{ABSTRACT}

In the present study, we demonstrate that Kaempferol inhibited survival and proliferation of established human hepatocellular carcinoma (HCC) cell lines (HepG2, Huh-7, BEL7402, and SMMC) and primary human HCC cells. Kaempferol treatment in HCC cells induced profound AMP-activated protein kinase (AMPK) activation, which led to Ulk1 phosphorylation, mTOR complex 1 inhibition and cell autophagy. Autophagy induction was reflected by Beclin-1/autophagy gene 5 upregulation and p62 degradation as well as light chain 3B (LC3B)-I to LC3B-II conversion and LC3B puncta formation. Inhibition of AMPK, via AMPKa1 shRNA or dominant negative mutation, reversed above signaling changes. AMPK inhibition also largely inhibited Kaempferolinduced cytotoxicity in HCC cells. Autophagy inhibition, by 3-methyaldenine or Beclin-1 shRNA, also protected HCC cells from Kaempferol. Kaempferol downregulated melanoma antigen 6, the AMPK ubiquitin ligase, causing AMPKa1 stabilization and accumulation. We conclude that Kaempferol inhibits human HCC cells via activating AMPK signaling.

\section{INTRODUCTION}

Hepatocellular carcinoma (HCC) is a major cause of cancer-related moralities [1-3]. HCC's five-year survival has been poor for those with advanced and/or metastatic cancers [1-3]. Yet, the incidence of this devastating disease has been rising [1-3]. The clinical treatment options for human HCC are very limited [4, 5]. Development of more efficient anti-hepatocellular carcinoma (HCC) agent is desperately needed [4-9].

Kaempferol is one key flavonol that is present in different fruits and vegetables $[10,11]$. It is also a wellknown Traditional Chinese Medicine showing different pharmacologic activities against atherosclerosis and hyperlipidemia [10, 11]. More importantly, Kaempferol has displayed anti-cancer activity against a number of cancer cells in experimental settings $[10,11]$. Its potential activity against human HCC cells, and more importantly, the underlying mechanisms are not fully studied $[10,11]$.
AMP-activated protein kinase (AMPK) is the primary energy sensor in mammalian cells $[12,13]$. Under stress conditions, activation of AMPK is responsible for maintaining homeostasis of cellular energy at both cellular and physiology levels [12-14]. Recent studies have proposed an anti-cancer function following AMPK activation [15-17]. At the molecule level, activation of AMPK could inhibit human cancer cells [16, 17] via regulating its downstream effectors, including activating p53 to induce cell cycle arrest and apoptosis [18-20]. AMPK activation may inhibit oncogenic mammalian target of rapamycin (mTOR) complex 1 (mTORC1) activation [21]. Further, AMPK serves as a major upstream signaling for cell autophagy induction [22, 23]. Additionally, sustained AMPK activation shall cause degradation of several oncogenic proteins [24]. In the current study, we provide evidences to suggest that activation of AMPK is responsible for Kaempferolinduced anti-HCC cell activity in vitro. 


\section{RESULTS}

\section{Kaempferol inhibits survival of established and primary human $\mathrm{HCC}$ cells}

First, Kaempferol, at different concentrations, was added to cultured HepG2 cells, which are wellestablished human HCC cells. Cells were then cultured in Kaempferol-containing medium for different time points (24-96 hours). Cell Counting Kit-8 (CCK-8) assay was performed to test cell survival. As displayed in Figure 1A, Kaempferol inhibited survival of HepG2 cells, and the CCK-8 OD was significantly decreased. Notably, the antisurvival activity by Kaempferol was both concentrationand time-dependent (Figure 1A). A low concentration of Kaempferol $(5 \mu \mathrm{M})$ was in-effective against HepG2 cells (Figure 1A). The IC-50 of Kaempferol was close to 25-50 $\mu \mathrm{M}$ (Figure 1A). It would require at least 48 hours for Kaempferol $(>25 \mu \mathrm{M})$ to exert significant anti-survival effect (Figure 1A). Additionally, the number of HepG2 colonies was decreased sharply following Kaempferol $(25-100 \mu \mathrm{M})$ treatment (Figure 1B), further confirming its anti-survival activity.

We also tested the potential activity of Kaempferol in other HCC cells. Three established human HCC cell lines, including Huh-7, BEL7402, and SMMC, were treated with Kaempferol ( $50 \mu \mathrm{M}$, for 72 hours). As shown in Figure 1C, cell survival, tested again by the CCK8 OD, was significantly decreased after Kaempferol treatment. Next, a total of three lines of primary human HCC cells (gifts from Dr. Sun [25]) were cultured. These primary cancer cells were treated with/out Kaempferol $(50 \mu \mathrm{M})$. CCK-8 assay results in Figure 1D confirmed that Kaempferol was anti-survival when added to all three lines of primary human HCC cells. On the other hand, very same Kaempferol ( $50 \mu \mathrm{M}, 72$ hours) treatment was yet non-cytotoxic to the L02 hepatocytes and primary human hepatocytes (provided by Dr. Fan [26]) (Figure 1E). The CCK-8 OD was almost unchanged following Kaempferol treatment in the hepatocytes (Figure 1E). These results demonstrate that Kaempferol inhibits survival of established and primary human HCC cells.

\section{Kaempferol inhibits HCC cell proliferation}

The Kaempferol-induced effect on HCC cell proliferation was tested next. 5-bromo-2'-deoxyuridine (BrdU) incorporation is a well-established marker of cell proliferation. As displayed in Figure 2A, treatment with Kaempferol dose-dependently decreased BrdU ELISA OD in HepG2 cells. Proliferation inhibition was significant at 24 hours after Kaempferol (25-100 $\mu \mathrm{M})$ treatment, when no significant cytotoxicity was noticed (Figure 1A). Similarly, Kaempferol $(50 \mu \mathrm{M})$ was also anti-proliferative when added to Huh-7 cells and primary human HCC cells ("Pri-1"), as BrdU ELISA OD was decreased (Figure 2B). Further, cell cycle distribution experimental results showed that after Kaempferol treatment, the percentages of S and G2-M phase HepG2 cells were decreased, and G1 phase cell percentage was increased, suggesting G1-S cell cycle arrest (Figure 2C). The very similar G1-S arrest effect by Kaempferol was also observed in the primary HCC cells ("Pri-1", Figure 2D). It should be noted that Kaempferol $(50 \mu \mathrm{M})$ treatment induced HepG2 and primary human HCC ("Pri-1") cell death (Figure 2E and $2 \mathrm{~F}$ ), the latter was reflected by the trypan blue staining assay.

\section{Kaempferol fails to induce $\mathrm{HCC}$ cell apoptosis}

Cell apoptosis activation could be an important cause of cell death and proliferation inhibition. We therefore tested apoptosis in Kaempferol-treated HCC cells. A set of various apoptosis assays were applied. The TUNEL assay results demonstrated that treatment with the cytotoxic Kaempferol $(50 \mu \mathrm{M})$ for different time points (24/48/72 hours) failed to induce significant apoptosis activation in HepG2 cells (Figure 3A). Meanwhile, the caspase-3 activity (Figure 3B), the Annexin $\mathrm{V}$ ratio (Figure 3C) and the histone DNA ELISA OD (Figure 3D) were unchanged after Kaempferol treatment in HepG2 cells. These results imply that Kaempferol failed to induce significant apoptosis in HepG2 cells. On the other hand, C8 ceramide $(25 \mu \mathrm{M}$, 48 hours), which was utilized as a positive control [27], induced profound apoptosis activation in HepG2 cells (Figure 3A-3D). Notably, Kaempferol treatment (50 $\mu \mathrm{M}, 48$ hours) also failed to increase TUNEL nuclei ratio in Huh-7 cells and primary human HCC cells ("Pri1") (Figure 3E). Certainly no apoptosis was induced in Kaempferol-treated primary human hepatocytes (Figure $3 E)$. These results suggest that Kaempferol fails to induce HCC cell apoptosis.

\section{Kaempferol induces autophagy activation in HCC cells}

Although autophagy could be pro-survival under certain circumstances, sustained autophagy activation shall induce cell death (autophagic cell death) [28-31]. The results mentioned above suggested that Kaempferol induced non-apoptotic cell death in HCC cells. We therefore tested potential autophagy induction in Kaempferol-treated HCC cells. Western blotting assay results showed that Kaempferol $(50 \mu \mathrm{M})$ treatment induced Beclin-1/autophagy gene 5 (ATG-5) upregulation, light chain 3B (LC3B) LC3B-I to LC3B-II conversion as well as p62 degradation in HepG2 cells. The effect by Kaempferol was time-dependent, suggesting autophagy flux $[32,33]$. The very similar changes on autophagyassociated proteins were also noticed in Kaempferoltreated primary HCC cells (Figure 4B). These results imply that Kaempferol induced autophagy activation in HCC cells. 

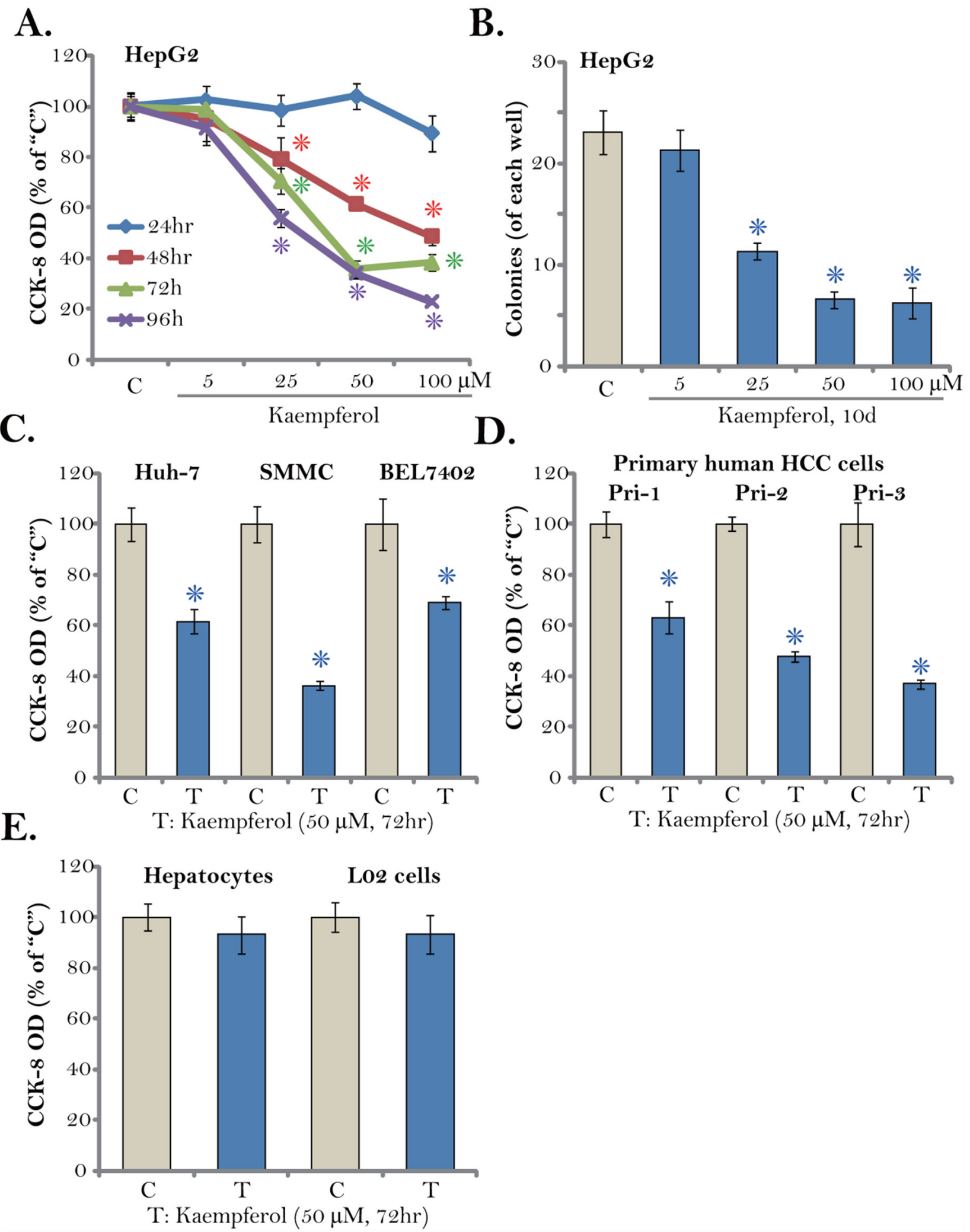

Figure 1: Kaempferol inhibits HCC cell survival. Established human HCC cell lines (HepG2, Huh-7, BEL7402, and SMMC), the primary human HCC cells ("Pri-1/-2/-3"), as well as L02 hepatocytes ("L02") and the primary human hepatocytes ("Hepatocytes") were cultured in Kaempferol $(5-100 \mu \mathrm{M})$-containing medium for the indicated time. Cell survival was tested by CCK-8 assay (A, C-E) and colony formation assay (B, HepG2 cells). The data were presented as mean \pm standard deviation (SD) (same for all figures). For each assay, $\mathrm{n}=5$. "C" stands for untreated control group (Same for all figures). ${ }^{*} p<0.05$ vs. "C" group. Experiments in this figure were repeated four times, and similar results were obtained. 
A. B.
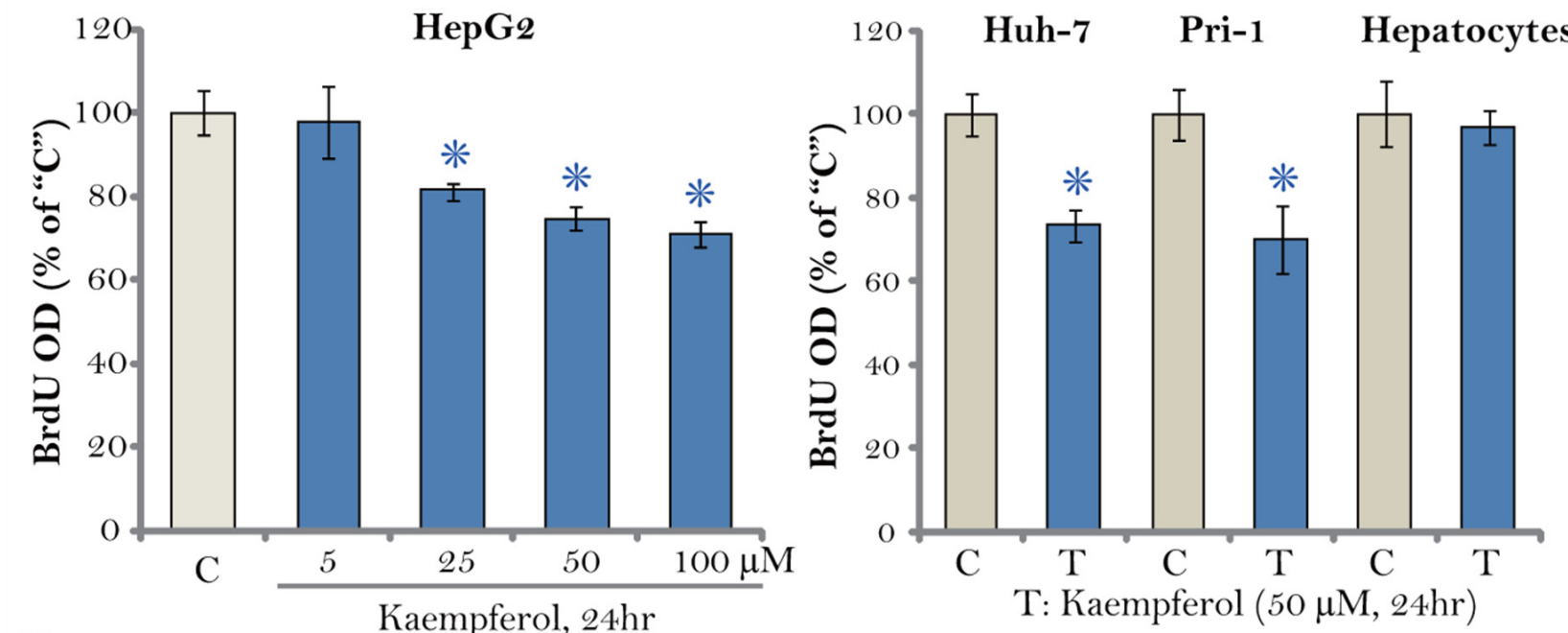

C.

D.
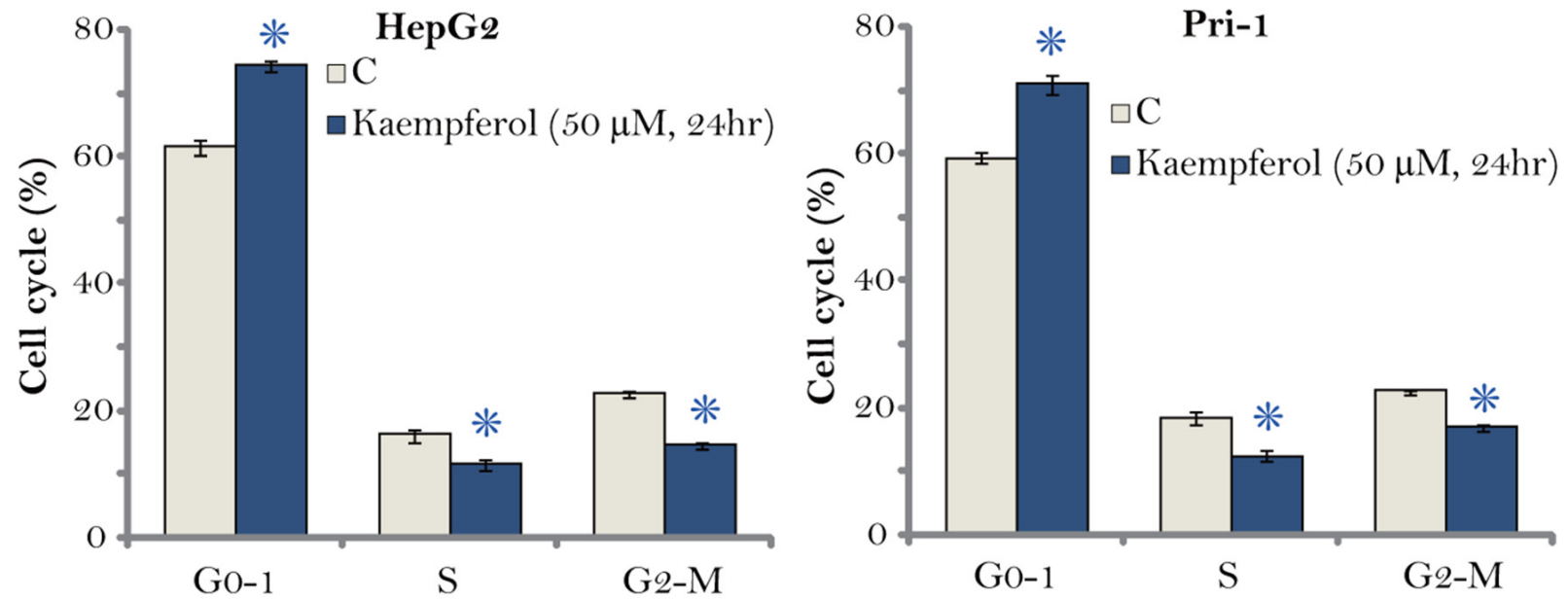

E.

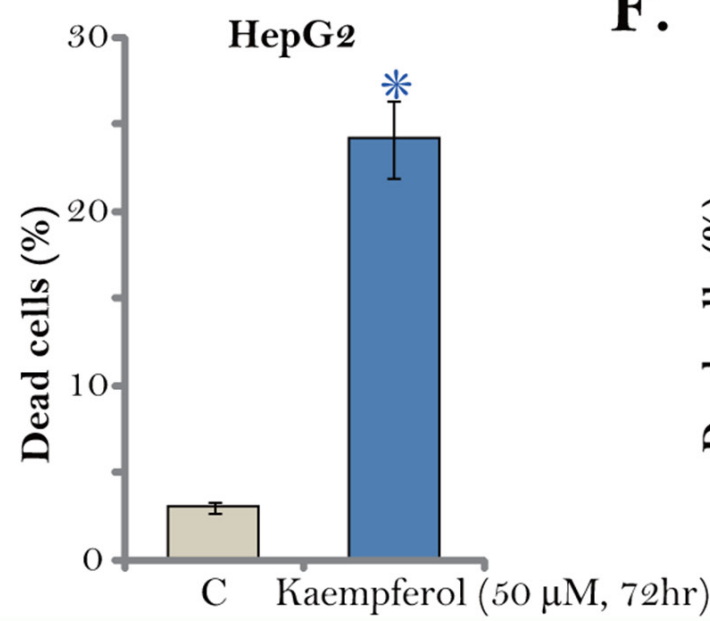

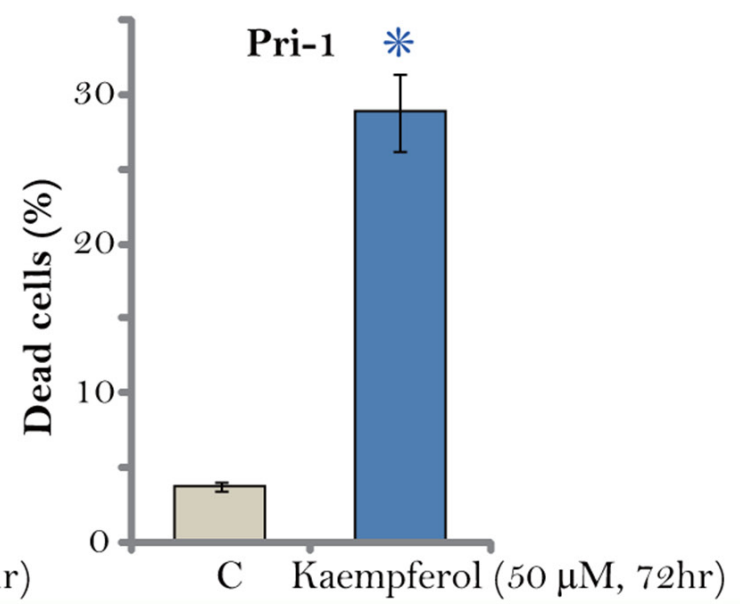

Figure 2: Kaempferol inhibits HCC cell proliferation. Established human HCC cell lines (HepG2 and Huh-7), the primary human HCC cells ("Pri-1"), or the primary human hepatocytes ("Hepatocytes") were cultured in Kaempferol (5-100 $\mu$ M)-containing medium for the indicated time. Cell proliferation (BrdU ELISA assay, A-B), cell cycle distribution (FACS assay, $\mathbf{C}$ and $\mathbf{D}$ ) and cell death (Trypan blue staining assay, $\mathbf{E}$ and $\mathbf{F}$ ) were tested. For each assay, $\mathrm{n}=5 .{ }^{*} p<0.05$ vs. "C" group. Experiments in this figure were repeated three times, and similar results were obtained. 
To study the link between autophagy activation and Kaempferol-induced cytotoxicity, both pharmacological and genetic strategies were applied to inhibit autophagy. 3-methyladenine (3-MA) is a well-established autophagy inhibitor [34, 35]. Further, a number of studies utilized Beclin-1 shRNA to genetically block autophagy [35]. In the current study, we show that 3-MA pre-treatment (for 1 hour) or Beclin-1 shRNA largely inhibited Kaempferol-induced HepG2 cell death (Figure 4C) and viability reduction (Figure 4D). These results suggest that autophagy activation is required for Kaempferol-induced cytotoxicity in HCC cells. Notably, Beclin-1 shRNA indeed efficiently downregulated Beclin-1 in Kaempferoltreated HepG2 cells (Figure 4D). Treatment with 3-MA or Beclin-1 shRNA alone failed to change survival/death of HCC cells (Figure 4C and 4D).

\section{AMPK activation is required for Kaempferol- induced autophagy and cytotoxicity in HCC cells}

One possible upstream kinase to trigger autophagy is AMPK $[22,36,37]$. In the current study, we show that Kaempferol $(50 \mu \mathrm{M})$ treatment in HepG2 cells induced significant AMPK activation (Figure 5A), which was reflected by phosphorylations ("p-") of AMPK $\alpha 1$ (Thr-172) and its major downstream effector protein acetyl-CoA carboxylase (ACC, Ser-79) [38, 39]. Expression level of total AMPKa1, intriguingly, was also significantly increased by Kaempferol (Figure 5A), which might contribute to AMPK activation. AMPK is known to directly phosphorylate Ulk1 at Ser-317 to initiate autophagy [22, 23]. Here, significant Ulk1 phosphorylation (at Ser-317) was noticed in Kaempferol-treated HepG2 cells (Figure 5B). AMPK-mediated autophagy activation could also be due to mTORC1 inhibition [22, 40]. We show that, following Kaempferol treatment, the phosphorylations of two major mTORC1 substrates, S6K1 (S6 Kinase 1) and 4EBP1 (eIF4E-binding protein 1), were both significantly reduced (Figure 5B), confirming mTORC1 in-activation [41].

To study the link between AMPK activation and Kaempferol-induced actions in HCC cells, AMPK $\alpha 1$ shRNA and the dominant negative mutant AMPK $\alpha 1$ (dn-
A.

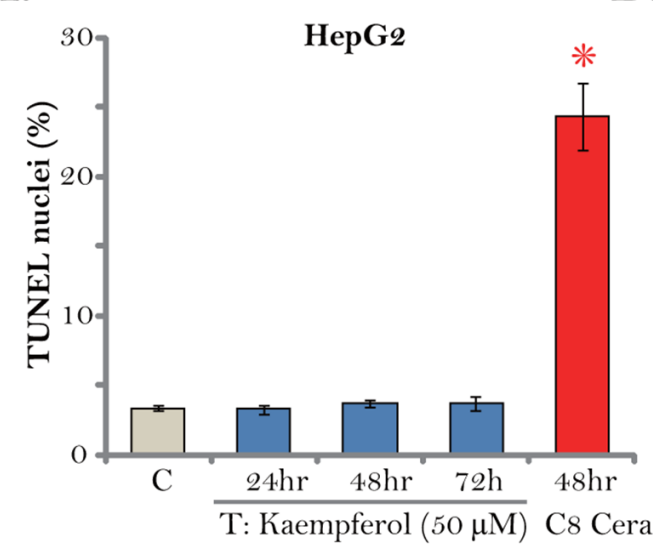

B.

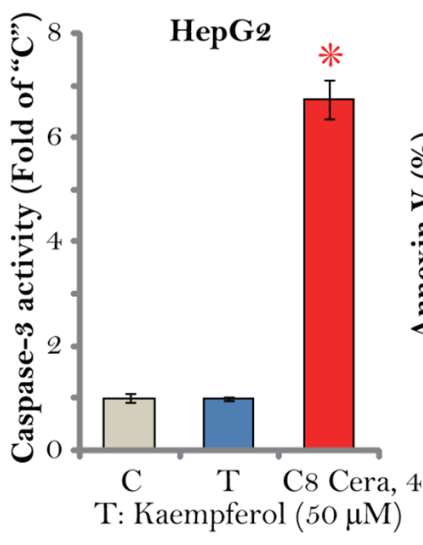

C.

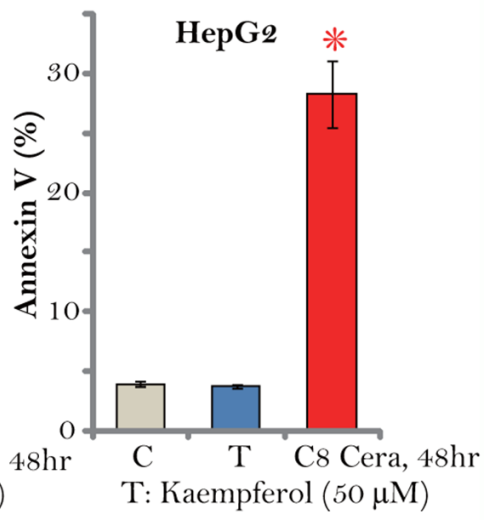

D.

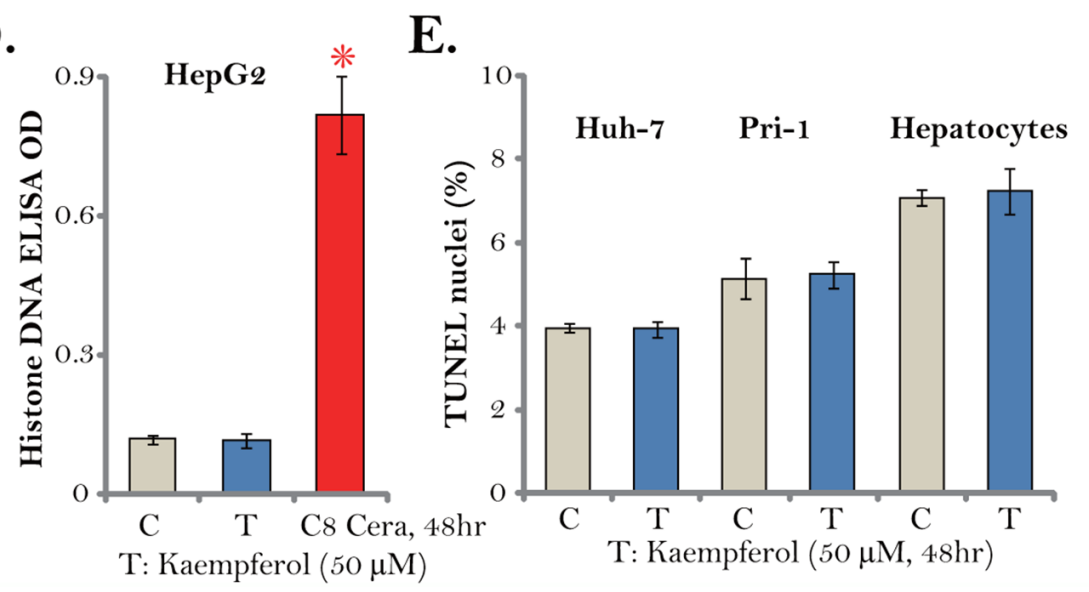

Figure 3: Kaempferol fails to induce HCC cell apoptosis. Established human HCC cell lines (HepG2 and Huh-7), the primary human HCC cells ("Pri-1"), or the primary human hepatocytes ("Hepatocytes") were cultured in Kaempferol (50 $\mu$ M)- or C8 ceramide ("C8 Cera", $25 \mu \mathrm{M}$ )-containing medium for the indicated time. Cell apoptosis was tested by the assays mentioned in the text. For each assay, $\mathrm{n}=5$. $* p<0.05$ vs. "C" group. Experiments in this figure were repeated four times, and similar results were obtained. 
AMPK $\alpha 1$, T172A) [42] were applied to block AMPK activation. The lentiviral AMPK $\alpha 1$ shRNA or the dnAMPK $\alpha 1$ (Flag-tagged, Figure 5C) was introduced to the HepG2 cells, and stable cells were established via puromycin selection. As displayed, Kaempferol-induced AMPK activation, or AMPK $\alpha 1 /$ ACC phosphorylations, were almost completely blocked by AMPK $\alpha 1$ shRNA or the dn-AMPK $\alpha 1$ (Figure 5C). More importantly, Kaempferol-induced Beclin-1 expression, Ulk1 phosphorylation and mTORC1 ("p-4EBP1") inhibition were largely attenuated by AMPK $\alpha 1$ shRNA or dnAMPK $\alpha 1$ (Figure 5D). Consequently, Kaempferolinduced autophagy induction, tested by the formation of
LC3B-GFP puncta, was largely inhibited (Figure 5E). These results suggest that AMPK activation mediates Kaempferol-induced Ulk1 phosphorylation, mTORC1 inhibition and autophagy induction in HCC cells.

We next hypothesized that AMPK activation should also be important for Kaempferol-mediated cytotoxicity. Indeed, in the stable HepG2 cells with AMPK $\alpha 1$ shRNA or the dn-AMPK $\alpha 1$, Kaempferolinduced cell viability reduction (Figure 5F) and cell death (Figure 5G) were largely attenuated. Thus, AMPK in-activation or knockdown protected HepG2 cells from Kaempferol, confirming that AMPK activation is required for Kaempferol-induced cytotoxicity against HepG2 cells.
A.

\section{HepG2}
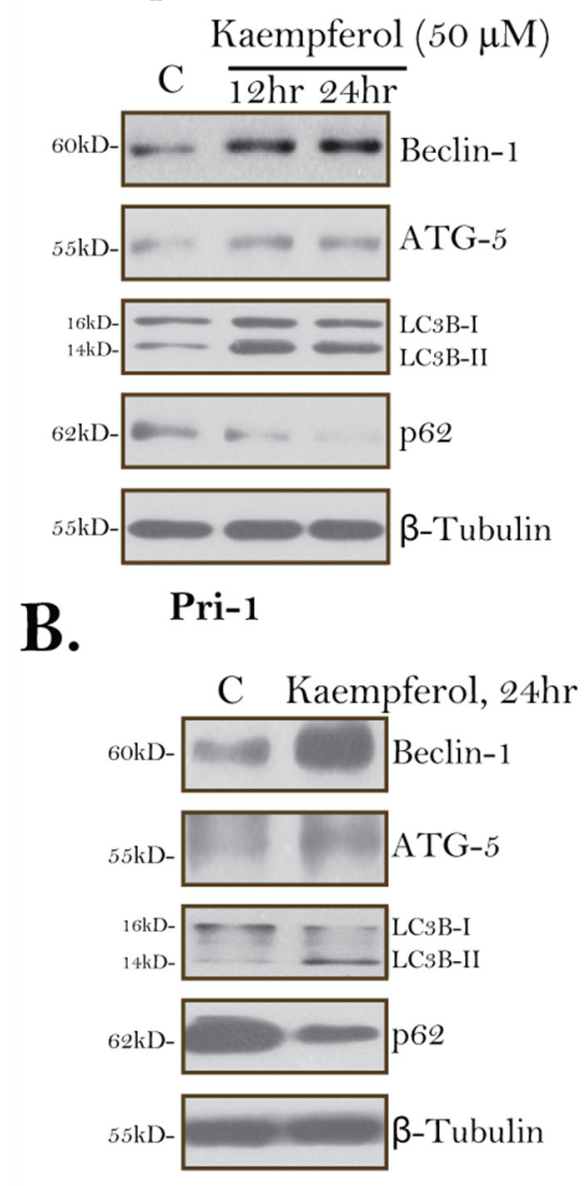

C.

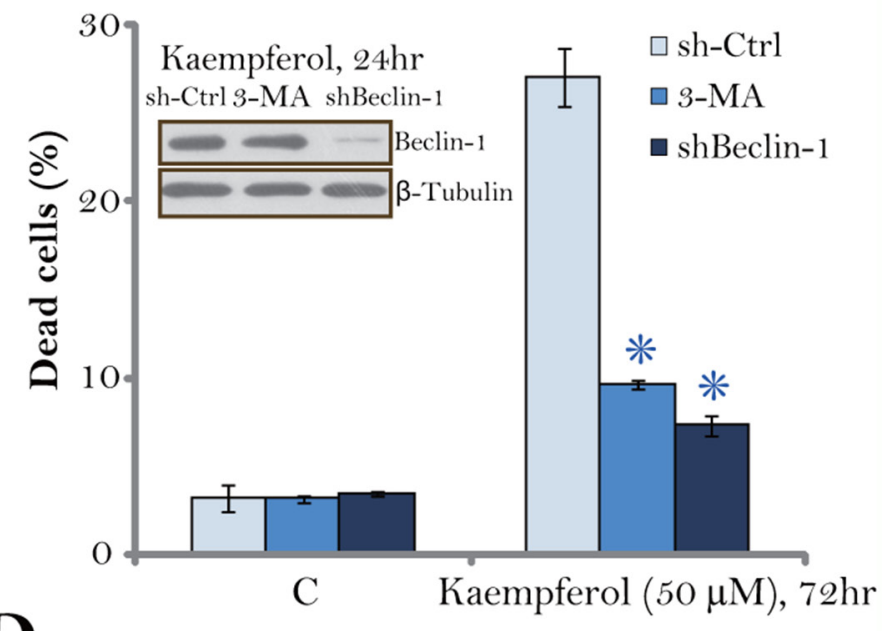

D.

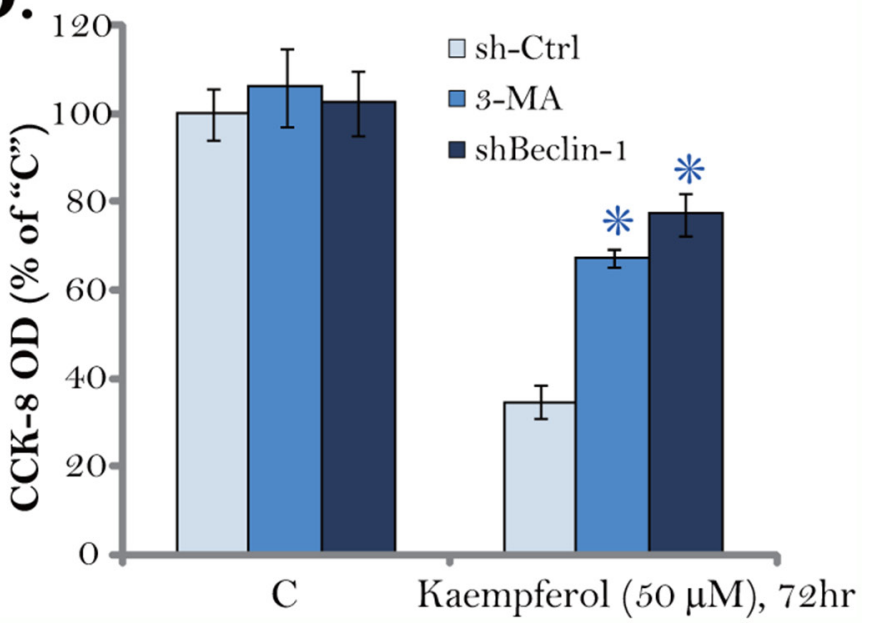

Figure 4: Kaempferol induces autophagy activation in HCC cells. HepG2 cells (A) or primary human HCC cells ("Pri-1", B) were cultured in Kaempferol $(50 \mu \mathrm{M})$-containing medium for the indicated time. Expressions of listed autophagy-associated proteins were shown. HepG2 cells were pre-treated with 3-methyladenine (3-MA, $5 \mathrm{mM}$, for 1 hour) or infected with Beclin-1 shRNA lentivirus, followed by Kaempferol $(50 \mu \mathrm{M})$ treatment for additional 72 hours, cell death and cell viability were tested by Trypan blue staining assay (C, lower panel) and CCK-8 assay (D), respectively. Expressions of Beclin-1 and $\beta$-Tubulin were also shown (C, upper panel). For each assay, $\mathrm{n}=5$. "sh-Ctrl" stands for scramble control shRNA. * $p<0.05$ vs. "sh-Ctrl" group. Experiments in this figure were repeated three times, and similar results were obtained. 
AMPK $\alpha 1$ shRNA or dn-AMPK $\alpha 1$ alone failed to change HepG2 cell survival/death (Figure 5F and 5G).

\section{Kaempferol downregulates melanoma antigen6 (MAGE6) in HCC cells}

The above results have demonstrated that AMPK activation mediated Kaempferol-induced cytotoxicity in $\mathrm{HCC}$ cells. We next tested the possible underlying mechanisms. We have shown that total AMPK $\alpha 1$ level was increased in Kaempferol-treated HCC cells (Figure 5). Pineda and colleagues have recently identified MAGEA6 as a cancer-specific AMPK $\alpha 1$ ubiquitin ligase [43]. We thus examined MAGEA6 expression in HepG2 cells following Kaempferol treatment. As shown in Figure 6A, MAGEA6 protein level was downregulated in Kaempferol $(50 \mu \mathrm{M})$-treated HepG2 cells. MAGEA6 downregulation started as early as 6 hours after Kaempferol treatment (Figure 6A, quantification). Further, real-time quantitative PCR assay (RT-qPCR) results demonstrated that MAGEA6 $m R N A$ expression was also decreased by Kaempferol (Figure 6B). On the other hand, AMPKal mRNA expression was unchanged (Figure 6B). Based on these results, we hypothesize that Kaempferol downregulates MAGEA6, the AMPK $\alpha 1$ ubiquitin ligase, to cause AMPK $\alpha 1$ stabilization and accumulation. This could be at least one mechanism for following AMPK activation.

\section{DISCUSSION}

Dysregulation and hyperactivation of mTORC1 is observed in human HCC $[9,44-46]$, which is a key procancerous cascade required for a number of oncogenic behaviors, including cell survival, growth [47-49] and apoptosis resistance as well as angiogenesis, cell migration and cancer metastasis $[9,25,35,50]$. Inactivation of mTORC1 represents a fine strategy to inhibit HCC cells $[9,25,35,50]$. One main downstream following AMPK activation is mTORC1 inhibition. AMPK is shown to directly phosphorylate tuberous sclerosis complex 2 (TSC2), the mTORC1 suppressor protein, causing mTORC1 inhibition [21, 51, 52]. Intriguingly, activated AMPK could also inhibit mTORC1 in TSC2-silenced or -mutated cells $[53,54]$. Later on, it was discovered that
A.

\section{HepG 2}

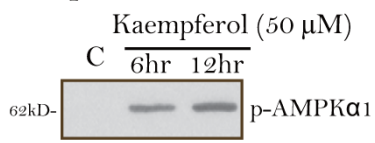

$=$ AMPKa 1
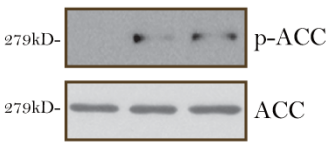

B.

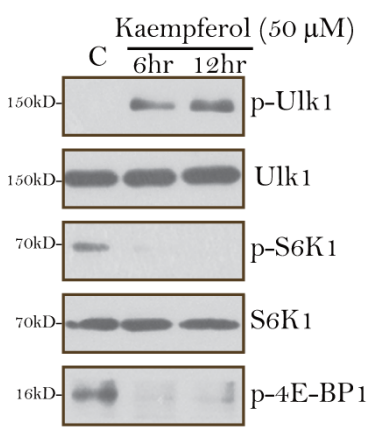

C. Kaempferol $(50 \mu \mathrm{M}), 12 \mathrm{hr}$
D.

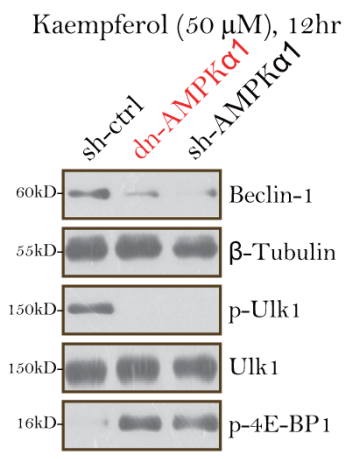

E.

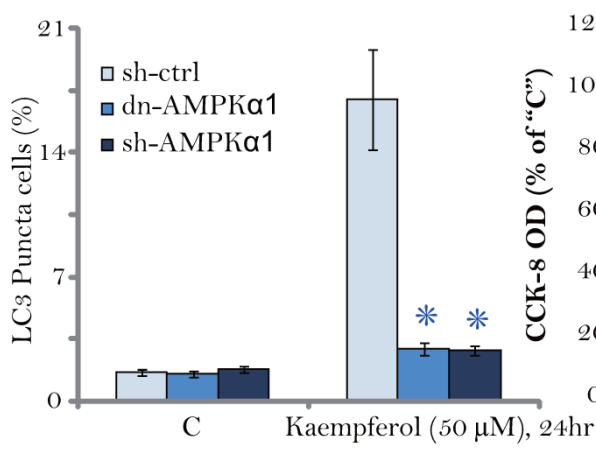

F.

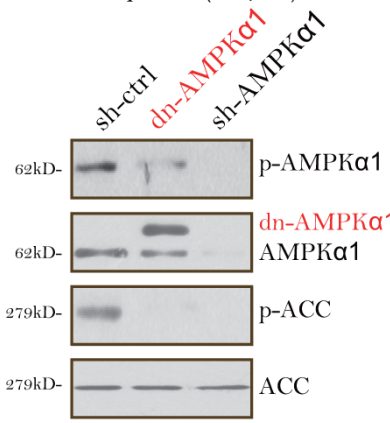

G.

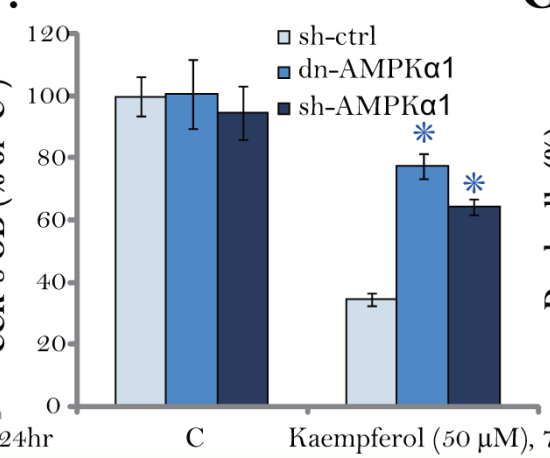

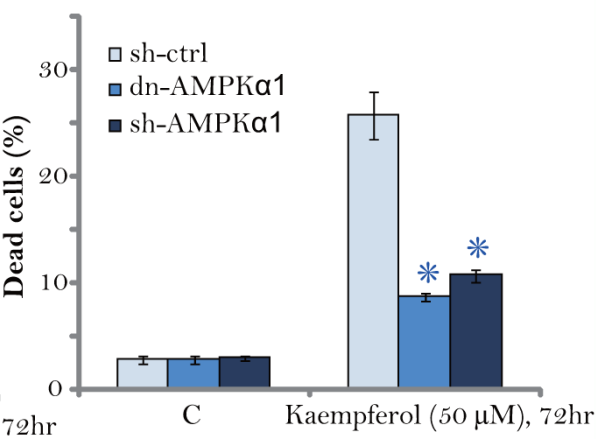

Figure 5: AMPK activation is required for Kaempferol-induced autophagy and cytotoxicity in HCC cells. HepG2 cells were cultured in Kaempferol $(50 \mu \mathrm{M})$-containing medium for the indicated time. Expressions of listed proteins were shown (A and B). Stable HepG2 cells, expressing AMPK $\alpha 1$ shRNA ("sh-AMPK $\alpha 1$ ") or the dominant negative AMPK $\alpha 1$ (T172A, Flag-tagged, "dnAMPK $\alpha 1$ "), were cultured in Kaempferol $(50 \mu \mathrm{M})$-containing medium for the indicated time. Expressions of listed proteins were shown (C and D). LC3 Puncta formation (E), cell viability (CCK-8 assay, F) and cell death (Trypan blue staining assay, G) were also tested. For each assay, $\mathrm{n}=5$. "sh-Ctrl" stands for scramble control shRNA. * $p<0.05$ vs. "sh-Ctrl" group. Experiments in this figure were repeated three times, and similar results were obtained. 
AMPK-mediated mTORC1 inhibition could also be due to its direct inhibition on Raptor $[55,56]$, the latter is key component of mTORC1 $[53,54]$. In the current study, we show that Kaempferol treatment in HCC cells significantly inhibited mTORC1 activation, or phosphorylations of mTORC1 substrates S6K1 and 4EBP1 [57, 58]. Further, activation of AMPK mediated Kaempferol-induced mTORC1 inhibition, as AMPK $\alpha 1$ shRNA or dominant negative mutation restored $\mathrm{mTORC} 1$ activation in Kaempferol-treated HCC cells.

Although minor or moderate cell autophagy could be pro-survival, recent studies have proposed that sustained and unresolved autophagy shall promote cancer cell death [59-61]. Indeed, a number of anti-cancer agents were shown to provoke cancer cell autophagic death (but not apoptosis) $[59,61,62]$. It is an alternative way to kill cancer cells when apoptosis was deficient or blocked [5961]. AMPK activation shall trigger autophagy activation directly and/or in-directly. AMPK directly associates, phosphorylates and activates Ulk1, which triggers cell autophagy [22]. Indirectly, AMPK-mediated mTORC1 inhibition shall remove inhibition on autophagy (by mTORC1 [22, 63]).

One novel finding of this study is that Kaempferol induced AMPK-dependent autophagy activation in HCC cells. Autophagy activation was reflected by Ulk1 phosphorylation, Beclin-1/ATG-5 upregulation and p62 degradation as well as LC3B-I to LC3B-II conversion and $\mathrm{LC} 3 \mathrm{~B}$ puncta formation. Autophagy inhibition, by 3-MA or Beclin-1 shRNA, protected HCC cells from
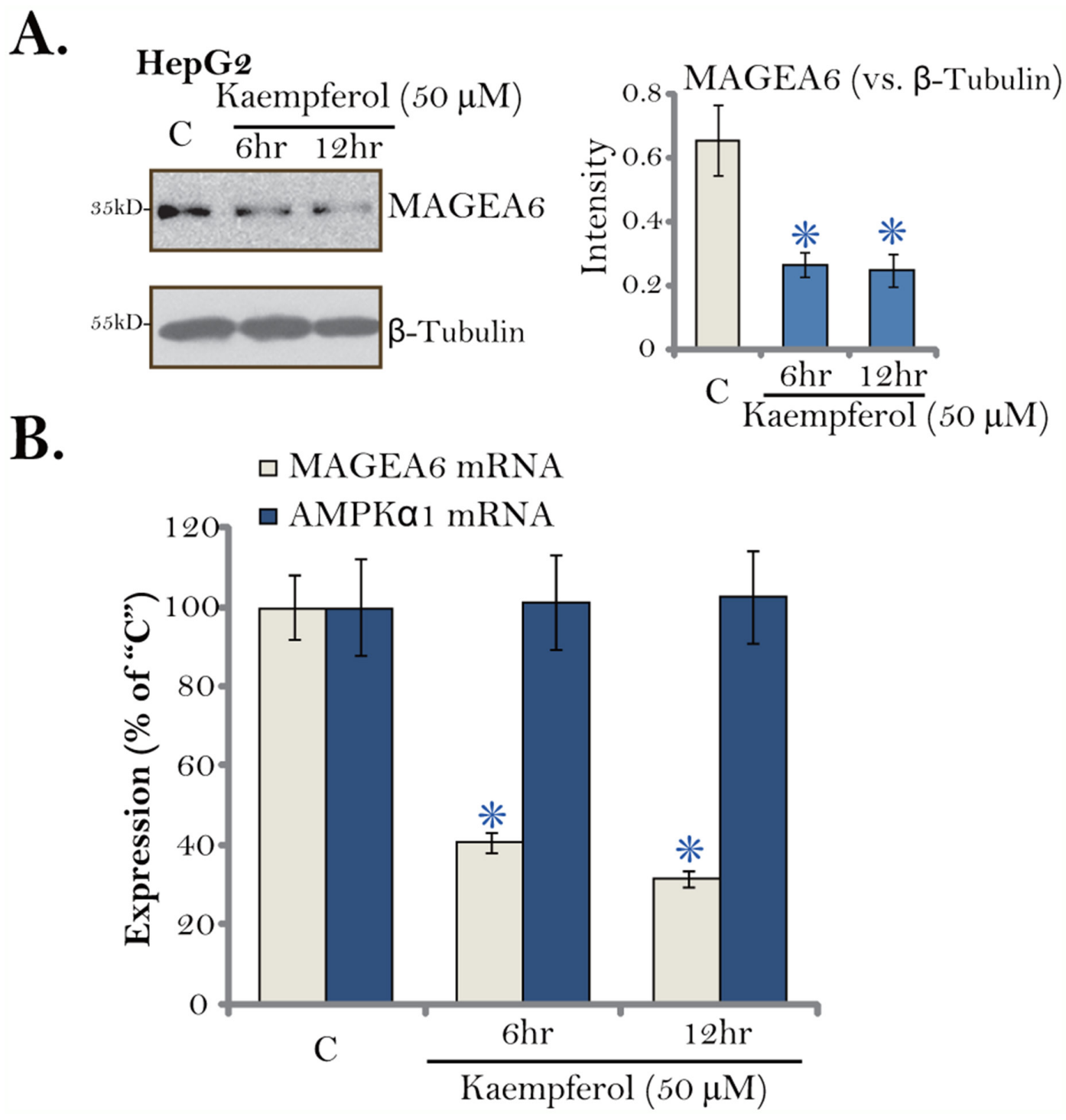

Figure 6: Kaempferol downregulates MAGE6 in HCC cells. HepG2 cells were cultured in Kaempferol (50 $\mu$ M)-containing medium for indicated time. Expressions of listed proteins were shown (A, data were quantified). Relative AMPKal mRNA and MAGE6 $m R N A$ expressions were also tested by RT-qPCR assay (B). For each assay, $\mathrm{n}=5$. ${ }^{*} p<0.05$ vs. "C" group. Experiments in this figure were repeated five times, and similar results were obtained. 
Kaempferol. Thus, Kaempferol apparently induced HCC cell autophagic cell death (but no apoptosis). Remarkably, Kaempferol-induced autophagy activation was almost abolished by AMPK shRNA or mutation. Consequently, HCC cell death by Kaempferol was also largely attenuated. Together, AMPK activation mediates Kaempferol-induced HCC cell autophagy and subsequent cell death.

The other key finding of this study is that Kaempferol treatment induced total AMPK $\alpha 1$ upregulation in $\mathrm{HCC}$ cells. The melanoma antigen (MAGE) genes encode a large family of MAGE proteins, all sharing a common homology domain [64, 65]. MAGEA6 is expressed exclusively in the male testis with unknown functions. It is however frequently re-expressed in various human cancers, which is involved in cancer cell progression [43]. A recent study Pineda et al., has confirmed MAGEA6 as the cancer-specific AMPK $\alpha 1$ ubiquitin ligase [43]. In the current study, we show that MAGEA6 expression is also detected in HCC cells, whose expression was downregulated by Kaempferol. MAGEA6 downregulation could be the primary reason of following AMPK $\alpha 1$ upregulation and activation. It will be certainly interesting to further test the mechanism of MAGEA6 downregulation by Kaempferol.

\section{MATERIALS AND METHODS}

\section{Reagents}

Kaempferol, 3-methyaldenine (3-MA) and puromycin were purchased from Sigma-Aldrich (Sigma, St. Louis, MO). C8 ceramide was a gift from Dr. Wang [27]. The anti-MAGEA6 antibody was obtained from Abcam (Shanghai, China). All the other antibodies were provided by Cell Signaling Tech Co. (Denver MA). The reagents for cell culture were from Gibco BRL (Suzhou, China).

\section{Culture of established human cell lines}

The established HCC cell lines, including HepG2, Huh-7, BEL7402, and SMMC, as well as the L02 hepatocyte cell line were purchased from the iBS cell bank of Fudan University (Shanghai, China). The HCC cells and L02 cells were maintained in DMEM/RPMI with $10 \%$ FBS and necessary antibiotics $[9,35]$.

\section{Primary culture of human HCC cells and human hepatocytes}

Three lines of the primary human HCC cells, namely "Pri-1/-2/-3", were provided by Dr. Sun [25]. These primary cancer cells were derived from surgeryisolated fresh HCC tissues of informed-consent primary HCC patients [25]. Cells were cultured in the medium for primary human cells. Fibroblast cultures were abandoned.
The primary human hepatocytes were provided by Dr. Fan [26], and cultured as previously described [26]. All investigations were in accordance with the principles expressed in the Declaration of Helsinki.

\section{CCK-8 cell viability assay}

Cells were plated at a density of $2 \times 10^{4}$ cells per well onto 96-well tissue-culture plates. Cells were further cultured in Kaempferol-containing medium for applied time. Afterwards, the cell viability was measured by Cell Counting Kit-8 (CCK-8) (Dojindo, Japan) kit with manufacturer's protocol. The OD value of the treatment group was normalized to the control group [66].

\section{Trypan blue staining of cell death}

Trypan blue staining assay was performed to test cell death.

\section{Colony formation assay}

HepG2 cells were initially plated at a density of 4 $\times 10^{5}$ cells per well onto six-well tissue-culture plates. Kaempferol-containing medium was renewed every 2 days for a total of 10 days. Afterwards, HepG2 colonies were stained and manually counted under the microscope.

\section{FACS assay}

After the applied Kaempferol treatment, cells were then stained with Annexin $\mathrm{V}$ and propidium iodide (PI) dyes (Biyuntian, Wuxi, China). Both early apoptotic cells (Annexin $\mathrm{V}^{+} / \mathrm{PI}^{-}$) and late apoptotic cells (Annexin $\mathrm{V} /$ $\mathrm{PI}^{+}$) were sorted by the Beckman Coulter fluorescenceactivated cell sorting (FACS) machine. Annexin V ratio was recorded. PI distribution was also analyzed to reflect cell cycle progression.

\section{Caspase-3 activity assay}

The CaspASE Assay System Colorimetric Kit (Promega, Nanjing, China) was applied to quantify caspase-3 activity [26]. Briefly, $20 \mu \mathrm{L}$ of cell lysis per treatment was mixed with $40 \mu \mathrm{L}$ caspase buffer. The reaction was started by adding $2 \mu \mathrm{L}$ DEVD-pNA (the caspase- 3 substrate), and incubated at $37^{\circ} \mathrm{C}$ for 2 hours [26]. The absorbance of the samples was measured spectrometrically at the wavelength of $405 \mathrm{~nm}$, reflecting caspase-3 activity, which was normalized to that of untreated control group.

\section{Enzyme-linked immunosorbent assay (ELISA) assay of cell apoptosis}

The Histone-DNA ELISA Detection Kit (Roche, Shanghai, China) was applied to test apoptosis of HCC 
cells/hepatocytes with applied treatment $[36,66,67]$. The ELISA OD at $405 \mathrm{~nm}$ was recorded.

\section{BrdU incorporation assay of cell proliferation}

The 5-bromo-2'-deoxyuridine (BrdU) ELISA assay kit (Cell Signaling Tech, Shanghai, China) was applied to quantify cell proliferation, via the recommended protocol.

\section{TUNEL assay of apoptosis}

Positive TUNEL staining in cell nuclei is a wellestablished indicator of cell apoptosis. HCC cells/ hepatocytes were stained with TUNEL fluorescence dye (Biyuntian, Wuxi, China). TUNEL ratio was recorded. At least 300 cells of five random views of each condition were counted.

\section{Western blotting assay}

Following the Kaempferol treatment, cells were homogenized in the commercial-available lysis buffer (Biyuntian, Wuxi, China). The protein lysates (30-40 $\mu \mathrm{g}$ per condition) were separated by $10-12.5 \%$ SDS-page gels, and were transferred onto polyvinylidene fluoride (PVDF) membranes (Millipore, Suzhou, China). The blots were then blocked, and incubated with designated primary and secondary antibodies. ECL Supersingnal West Pico Chemiluminescent kit was utilized to visualize the targeted protein bands.

\section{LC3B immunochemistry staining assay}

As described previously [66, 68], HepG2 cells were fixed, and were then incubated with the primary antiLC3B antibody (GFP-conjugated, Genepharm, Shanghai, China). LC3B GFP fluorescence was visualized under the Leica microscope. The percentage of HepG2 cells with LC3B GFP puncta (vs. total cell number, Hoechst stained) was recorded $[66,68]$. For each condition, at least 100 cells in each view were counted.

\section{ShRNA}

The lentiviral participles with Beclin-1 shRNA (sc29797-V), AMPK $\alpha 1$-shRNA (sc-45312-V) or scramble control shRNA (sc-108065) were purchase from Santa Cruz Biotech (Shanghai, China). HCC cells were seeded onto six-well plates at $50 \%$ confluence. After 12 hours culture in serum free medium, $20 \mu \mathrm{L} / \mathrm{mL}$ of the lentiviral shRNA was added for additional 24 hours. Cells were then subjected to puromycin $(2.5 \mu \mathrm{g} / \mathrm{mL}$, Sigma) selection for another 48 hours. The Beclin-1/AMPK $\alpha 1$ knockdown in the stable cells was tested by Western blotting assay.

\section{AMPKa1 dominant negative mutation}

The dominant negative AMPK $\alpha 1$ (dn-AMPK $\alpha 1$, T172A) construct was provided by Dr. Lu P. H. at Nanjing Medical University. HCC cells were seeded onto sixwell plates at $50 \%$ confluence. After 12 hours culture in serum free medium, dn-AMPK $\alpha(0.10 \mu \mathrm{g} / \mathrm{mL}$ medium $)$ or the empty vector (pSuper-puro-Flag) was transfected to the HCC cells by the Lipofectamine 2000 reagent. Cells were then subjected to puromycin $(2.5 \mu \mathrm{g} / \mathrm{mL}$, Sigma $)$ selection for additional 48 hours. Transfection efficiency was verified via Western blotting assay of endogenous and exogenous AMPK $\alpha 1$ expression.

\section{Real-time quantitative PCR assay}

The Stat60 reagents were applied to extract total cellular RNA. The protocol of real-time quantitative reverse transcriptase polymerase chain reaction ("RTqPCR") assay by the ABI Prism 7600 Fast Real-Time PCR system was described previously [66]. The $2^{-\Delta \Delta C t}$ method was applied to calculate relative mRNA expression level [69]. Glyceraldehyde-3-phosphate dehydrogenase (GAPDH) was always tested as the internal control [66]. The $m R N A$ primers for human AMPK $\alpha 1$ and MAGEA6 were described early [43].

\section{Statistical analysis}

The data were presented as mean \pm standard deviation (SD). Statistical differences were analyzed by one-way ANOVA with post hoc Bonferroni test (SPSS version 18.0). Values of $\mathbf{p}<0.05$ were considered statistically different.

\section{CONCLUSION}

We suggest that Kaempferol inhibits human HCC cells via activating AMPK signaling. Kaempferol could be further tested as a promising anti-HCC agent.

\section{Author contributions}

All authors carried out the experiments, participated in the design of the study and performed the statistical analysis, participated in its design and coordination and helped to draft the manuscript.

\section{ACKNOWLEDGMENTS AND FUNDING}

A project of "The effect of traditional Chinese medicine "Xie Li Yin Yang Tang" on experimental model of perimenopausal syndrome", project supported by the Minhang Science Foundation of China (Grant No. 2016MHZ29) 


\section{CONFLICTS OF INTEREST}

The authors have no conflicts of interests.

\section{REFERENCES}

1. Siegel RL, Miller KD, Jemal A. Cancer statistics, 2017. CA Cancer J Clin. 2017; 67:7-30.

2. Siegel RL, Miller KD, Jemal A. Cancer statistics, 2016. CA Cancer J Clin. 2016; 66:7-30.

3. Chen W, Zheng R, Baade PD, Zhang S, Zeng H, Bray F, Jemal A, Yu XQ, He J. Cancer statistics in China, 2015. CA Cancer J Clin. 2016; 66:115-132.

4. Llovet JM, Bruix J. Systematic review of randomized trials for unresectable hepatocellular carcinoma: chemoembolization improves survival. Hepatology. 2003; 37:429-442.

5. Yang JD, Roberts LR. Hepatocellular carcinoma: a global view. Nat Rev Gastroenterol Hepatol. 2010; 7:448-458.

6. Farazi PA, DePinho RA. Hepatocellular carcinoma pathogenesis: from genes to environment. Nat Rev Cancer. 2006; 6:674-687.

7. Wu Z, Zeng Q, Cao K, Sun Y. Exosomes: small vesicles with big roles in hepatocellular carcinoma. Oncotarget. 2016; 7:60687-60697. https://doi.org/10.18632/oncotarget. 10807 .

8. Su H, Li B, Zheng L, Wang H, Zhang L. Immunotherapy based on dendritic cells pulsed with CTPFoxM1 fusion protein protects against the development of hepatocellular carcinoma. Oncotarget. 2016; 7:48401-48411. https://doi. org/10.18632/oncotarget.10269.

9. Chen MB, Zhou ZT, Yang L, Wei MX, Tang M, Ruan TY, Xu JY, Zhou XZ, Chen G, Lu PH. KU-0060648 inhibits hepatocellular carcinoma cells through DNA-PKcsdependent and DNA-PKcs-independent mechanisms. Oncotarget. 2016; 7:17047-17059. https://doi.org/10.18632/ oncotarget. 7742 .

10. Kim SH, Choi KC. Anti-cancer effect and underlying mechanism(s) of kaempferol, a phytoestrogen, on the regulation of apoptosis in diverse cancer cell models. Toxicol Res. 2013; 29:229-234.

11. Chen AY, Chen YC. A review of the dietary flavonoid, kaempferol on human health and cancer chemoprevention. Food Chem. 2013; 138:2099-2107.

12. Shackelford DB, Shaw RJ. The LKB1-AMPK pathway: metabolism and growth control in tumour suppression. Nat Rev Cancer. 2009; 9:563-575.

13. Mihaylova MM, Shaw RJ. The AMPK signalling pathway coordinates cell growth, autophagy and metabolism. Nat Cell Biol. 2011; 13:1016-1023.

14. Vakana E, Altman JK, Platanias LC. Targeting AMPK in the treatment of malignancies. J Cell Biochem. 2012; 113:404-409.
15. Zhao Z, Feng L, Wang J, Cheng D, Liu M, Ling M, Xu W, Sun K. NPC-26 kills human colorectal cancer cells via activating AMPK signaling. Oncotarget. 2017; 8:1831218321. https://doi.org/10.18632/oncotarget.15436.

16. Lu PH, Chen MB, Ji C, Li WT, Wei MX, Wu MH. Aqueous Oldenlandia diffusa extracts inhibits colorectal cancer cells via activating AMP-activated protein kinase signalings. Oncotarget. 2016; 7:45889-45900. https://doi.org/10.18632/ oncotarget.9969.

17. Law BY, Mok SW, Chan WK, Xu SW, Wu AG, Yao XJ, Wang JR, Liu L, Wong VK. Hernandezine, a novel AMPK activator induces autophagic cell death in drug-resistant cancers. Oncotarget. 2016; 7:8090-8104. https://doi. org/10.18632/oncotarget.6980.

18. Zhang WB, Wang Z, Shu F, Jin YH, Liu HY, Wang QJ, Yang Y. Activation of AMP-activated protein kinase by temozolomide contributes to apoptosis in glioblastoma cells via 553 activation and $\mathrm{mTORC} 1$ inhibition. J Biol Chem. 2010; 285:40461-40471.

19. Nieminen AI, Eskelinen VM, Haikala HM, Tervonen TA, Yan Y, Partanen JI, Klefstrom J. Myc-induced AMPK-phospho p53 pathway activates Bak to sensitize mitochondrial apoptosis. Proc Natl Acad Sci U S A. 2013; 110:E1839-1848.

20. Jones RG, Plas DR, Kubek S, Buzzai M, Mu J, Xu Y, Birnbaum MJ, Thompson CB. AMP-activated protein kinase induces a p53-dependent metabolic checkpoint. Mol Cell. 2005; 18:283-293.

21. Inoki K, Zhu T, Guan KL. TSC2 mediates cellular energy response to control cell growth and survival. Cell. 2003; 115:577-590.

22. Kim J, Kundu M, Viollet B, Guan KL. AMPK and mTOR regulate autophagy through direct phosphorylation of Ulk1. Nat Cell Biol. 2011; 13:132-141.

23. Egan DF, Shackelford DB, Mihaylova MM, Gelino S, Kohnz RA, Mair W, Vasquez DS, Joshi A, Gwinn DM, Taylor R, Asara JM, Fitzpatrick J, Dillin A, et al. Phosphorylation of ULK1 (hATG1) by AMP-activated protein kinase connects energy sensing to mitophagy. Science. 2011; 331:456-461.

24. Wu WD, Hu ZM, Shang MJ, Zhao DJ, Zhang CW, Hong DF, Huang DS. Cordycepin down-regulates multiple drug resistant (MDR)/HIF-1alpha through regulating AMPK/ mTORC1 signaling in GBC-SD gallbladder cancer cells. Int J Mol Sci. 2014; 15:12778-12790.

25. Xie Z, Wang J, Liu M, Chen D, Qiu C, Sun K. CC-223 blocks mTORC1/C2 activation and inhibits human hepatocellular carcinoma cells in vitro and in vivo. PLoS One. 2017; 12:e0173252.

26. Liu M, Gu P, Guo W, Fan X. C6 ceramide sensitizes the anti-hepatocellular carcinoma (HCC) activity by AZD8055, a novel mTORC1/2 dual inhibitor. Tumour Biol. 2016; 37:11039-11048. 
27. Lv H, Zhang Z, Wu X, Wang Y, Li C, Gong W, Gui L, Wang X. Preclinical evaluation of liposomal C8 ceramide as a potent anti-hepatocellular carcinoma agent. PLoS One. 2016; 11:e0145195.

28. Reyjal J, Cormier K, Turcotte S. Autophagy and cell death to target cancer cells: exploiting synthetic lethality as cancer therapies. Adv Exp Med Biol. 2014; 772:167-188.

29. Marino G, Niso-Santano M, Baehrecke EH, Kroemer G. Self-consumption: the interplay of autophagy and apoptosis. Nat Rev Mol Cell Biol. 2014; 15:81-94.

30. Rubinsztein DC, Codogno P, Levine B. Autophagy modulation as a potential therapeutic target for diverse diseases. Nat Rev Drug Discov. 2012; 11:709-730.

31. Ouyang L, Shi Z, Zhao S, Wang FT, Zhou TT, Liu B, Bao JK. Programmed cell death pathways in cancer: a review of apoptosis, autophagy and programmed necrosis. Cell Prolif. 2012; 45:487-498.

32. Mitter SK, Song C, Qi X, Mao H, Rao H, Akin D, Lewin A, Grant M, Dunn W Jr, Ding J, Bowes Rickman C, Boulton M. Dysregulated autophagy in the RPE is associated with increased susceptibility to oxidative stress and AMD. Autophagy. 2014; 10:1989-2005.

33. Adiseshaiah PP, Clogston JD, McLeland CB, Rodriguez J, Potter TM, Neun BW, Skoczen SL, Shanmugavelandy SS, Kester M, Stern ST, McNeil SE. Synergistic combination therapy with nanoliposomal C6-ceramide and vinblastine is associated with autophagy dysfunction in hepatocarcinoma and colorectal cancer models. Cancer Lett. 2013; 337:254-265.

34. Zhu YR, Zhou XZ, Zhu LQ, Yao C, Fang JF, Zhou F, Deng $\mathrm{XW}$, Zhang YQ. The anti-cancer activity of the mTORC1/2 dual inhibitor XL388 in preclinical osteosarcoma models. Oncotarget. 2016; 7:49527-49538. https://doi.org/10.18632/ oncotarget.10389.

35. Zhang Q, Yang M, Qu Z, Zhou J, Jiang Q. Autophagy prevention sensitizes AKTi-1/2-induced anti-hepatocellular carcinoma cell activity in vitro and in vivo. Biochem Biophys Res Commun. 2016; 480:334-340.

36. She C, Zhu LQ, Zhen YF, Wang XD, Dong QR. Activation of AMPK protects against hydrogen peroxide-induced osteoblast apoptosis through autophagy induction and NADPH maintenance: new implications for osteonecrosis treatment? Cell Signal. 2014; 26:1-8.

37. Khan SH, Kumar R. Role of an intrinsically disordered conformation in AMPK-mediated phosphorylation of ULK1 and regulation of autophagy. Mol Biosyst. 2012; 8:91-96.

38. Minokoshi Y, Kim YB, Peroni OD, Fryer LG, Muller C, Carling D, Kahn BB. Leptin stimulates fatty-acid oxidation by activating AMP-activated protein kinase. Nature. 2002; 415:339-343.

39. Tomas E, Tsao TS, Saha AK, Murrey HE, Zhang Cc C, Itani SI, Lodish HF, Ruderman NB. Enhanced muscle fat oxidation and glucose transport by ACRP30 globular domain: acetyl-CoA carboxylase inhibition and AMPactivated protein kinase activation. Proc Natl Acad Sci U S A. 2002; 99:16309-16313.

40. Din FV, Valanciute A, Houde VP, Zibrova D, Green KA, Sakamoto K, Alessi DR, Dunlop MG. Aspirin inhibits mTOR signaling, activates AMP-activated protein kinase, and induces autophagy in colorectal cancer cells. Gastroenterology. 2012; 142:1504-1515.e1503.

41. Saxton RA, Sabatini DM. mTOR signaling in growth, metabolism, and disease. Cell. 2017; 168:960-976.

42. Li P, Fan JB, Gao Y, Zhang M, Zhang L, Yang N, Zhao X. miR-135b-5p inhibits LPS-induced TNFalpha production via silencing AMPK phosphatase Ppm1e. Oncotarget. 2016; 7:77978-77986. https://doi.org/10.18632/oncotarget.12866.

43. Pineda CT, Ramanathan S, Fon Tacer K, Weon JL, Potts MB, Ou YH, White MA, Potts PR. Degradation of AMPK by a cancer-specific ubiquitin ligase. Cell. 2015; 160:715-728.

44. Monaco AP. The role of mTOR inhibitors in the management of posttransplant malignancy. Transplantation. 2009; 87:157-163.

45. Llovet JM, Bruix J. Molecular targeted therapies in hepatocellular carcinoma. Hepatology. 2008; 48:1312-1327.

46. Ashworth RE, Wu J. Mammalian target of rapamycin inhibition in hepatocellular carcinoma. World J Hepatol. 2014; 6:776-782.

47. Ji J, Tang J, Deng L, Xie Y, Jiang R, Li G, Sun B. LINC00152 promotes proliferation in hepatocellular carcinoma by targeting EpCAM via the mTOR signaling pathway. Oncotarget. 2015; 6:42813-42824. https://doi. org/10.18632/oncotarget.5970.

48. Simioni C, Cani A, Martelli AM, Zauli G, Alameen AA, Ultimo S, Tabellini G, McCubrey JA, Capitani S, Neri LM. The novel dual PI3K/mTOR inhibitor NVP-BGT226 displays cytotoxic activity in both normoxic and hypoxic hepatocarcinoma cells. Oncotarget. 2015; 6:17147-17160. https://doi.org/10.18632/oncotarget.3940.

49. Yang YM, Lee CG, Koo JH, Kim TH, Lee JM, An J, Kim KM, Kim SG. Galpha12 overexpressed in hepatocellular carcinoma reduces microRNA-122 expression via HNF4alpha inactivation, which causes c-Met induction. Oncotarget. 2015; 6:19055-19069. https://doi.org/10.18632/ oncotarget. 3957.

50. Zhang W, Chen B, Zhang Y, Li K, Hao K, Jiang L, Wang Y, Mou X, Xu X, Wang Z. The anti-hepatocellular carcinoma cell activity by a novel mTOR kinase inhibitor CZ415. Biochem Biophys Res Commun. 2017; 487:494-499.

51. Inoki K, Ouyang H, Zhu T, Lindvall C, Wang Y, Zhang X, Yang Q, Bennett C, Harada Y, Stankunas K, Wang CY, He X, MacDougald OA, et al. TSC2 integrates Wnt and energy signals via a coordinated phosphorylation by AMPK and GSK3 to regulate cell growth. Cell. 2006; 126:955-968. 
52. Mak BC, Yeung RS. The tuberous sclerosis complex genes in tumor development. Cancer Invest. 2004; 22:588-603.

53. Garcia D, Shaw RJ. AMPK: mechanisms of cellular energy sensing and restoration of metabolic balance. Mol Cell. 2017; 66:789-800.

54. Hardie DG, Schaffer BE, Brunet A. AMPK: an energysensing pathway with multiple inputs and outputs. Trends Cell Biol. 2016; 26:190-201.

55. Gwinn DM, Shackelford DB, Egan DF, Mihaylova MM, Mery A, Vasquez DS, Turk BE, Shaw RJ. AMPK phosphorylation of raptor mediates a metabolic checkpoint. Mol Cell. 2008; 30:214-226.

56. Hardie DG. AMPK and Raptor: matching cell growth to energy supply. Mol Cell. 2008; 30:263-265.

57. Li ZW, Cai S, Liu Y, Yang CL, Tian Y, Chen G, Cao C. Over-expression of Galphai3 in human glioma is required for Akt-mTOR activation and cell growth. Oncotarget. 2016 Aug 1. https://doi.org/10.18632/oncotarget.10995. [Epub ahead of print].

58. Li X, Wu C, Chen N, Gu H, Yen A, Cao L, Wang E, Wang L. PI3K/Akt/mTOR signaling pathway and targeted therapy for glioblastoma. Oncotarget. 2016; 7:33440-33450. https:// doi.org/10.18632/oncotarget.7961.

59. Li Y, Zhang J, Chen X, Liu T, He W, Chen Y, Zeng X. Molecular machinery of autophagy and its implication in cancer. Am J Med Sci. 2012; 343:155-161.

60. Kondo Y, Kanzawa T, Sawaya R, Kondo S. The role of autophagy in cancer development and response to therapy. Nat Rev Cancer. 2005; 5:726-734.

61. Janku F, McConkey DJ, Hong DS, Kurzrock R. Autophagy as a target for anticancer therapy. Nat Rev Clin Oncol. 2011; 8:528-539.
62. Chaabane W, User SD, El-Gazzah M, Jaksik R, Sajjadi E, Rzeszowska-Wolny J, Los MJ. Autophagy, apoptosis, mitoptosis and necrosis: interdependence between those pathways and effects on cancer. Arch Immunol Ther Exp (Warsz). 2013; 61:43-58.

63. Jung CH, Jun CB, Ro SH, Kim YM, Otto NM, Cao J, Kundu M, Kim DH. ULK-Atg13-FIP200 complexes mediate mTOR signaling to the autophagy machinery. Mol Biol Cell. 2009; 20:1992-2003.

64. Feng Y, Gao J, Yang M. When MAGE meets RING: insights into biological functions of MAGE proteins. Protein Cell. 2011; 2:7-12.

65. Chomez P, De Backer O, Bertrand M, De Plaen E, Boon T, Lucas S. An overview of the MAGE gene family with the identification of all human members of the family. Cancer Res. 2001; 61:5544-5551.

66. Zhu LQ, Zhen YF, Zhang Y, Guo ZX, Dai J, Wang XD. Salinomycin activates AMP-activated protein kinasedependent autophagy in cultured osteoblastoma cells: a negative regulator against cell apoptosis. PLoS One. 2013; 8:e84175.

67. Zhen YF, Wang GD, Zhu LQ, Tan SP, Zhang FY, Zhou XZ, Wang XD. P53 dependent mitochondrial permeability transition pore opening is required for dexamethasoneinduced death of osteoblasts. J Cell Physiol. 2014; 229:1475-1483.

68. Zhen YF, Li ST, Zhu YR, Wang XD, Zhou XZ, Zhu LQ. Identification of DNA-PKcs as a primary resistance factor of salinomycin in osteosarcoma cells. Oncotarget. 2016; 7:79417-79427. https://doi.org/10.18632/oncotarget.12712.

69. Livak KJ, Schmittgen TD. Analysis of relative gene expression data using real-time quantitative PCR and the 2(-Delta Delta C(T)) Method. Methods. 2001; 25:402-408. 